\title{
A Comparison between Atlantic Canadian and National Correction Equations to Improve the Accuracy of Self-Reported Obesity Estimates in Atlantic Canada
}

\author{
Cynthia L. Murray, ${ }^{1}$ Gordon W. Walsh, ${ }^{2}$ and Sarah Connor Gorber ${ }^{3}$ \\ ${ }^{1}$ School of Nursing, Memorial University, St. John's, NL, Canada A1B 3V6 \\ ${ }^{2}$ Surveillance and Epidemiology Unit, Cancer Care Nova Scotia, Halifax, NS, Canada B3H 2 Y9 \\ ${ }^{3}$ Center for Chronic Disease Prevention and Control, Public Health Agency of Canada, Ottawa, ON, Canada K1A OK9
}

Correspondence should be addressed to Cynthia L. Murray, cindym@mun.ca

Received 10 September 2012; Accepted 9 November 2012

Academic Editor: Yvon Chagnon

Copyright ( $) 2012$ Cynthia L. Murray et al. This is an open access article distributed under the Creative Commons Attribution License, which permits unrestricted use, distribution, and reproduction in any medium, provided the original work is properly cited.

\begin{abstract}
Objectives. To determine whether obesity correction equations for the Canadian general population, which are dependent on the prevalence of obesity, are appropriate for use in Atlantic Canada, which has the highest obesity rates in the country. Also, to compare the accuracy of the national equations to equations developed specifically for the Atlantic Canadian population. Methods. The dataset consisted of Canadian Community Health Survey (CCHS) 2007-2008 data collected on 17,126 Atlantic Canadians and a subsample of adults, who provided measured height and weight (MHW) data. Atlantic correction equations were developed in the MHW subsample. Using separate multiple regression models for men and women, self-reported body mass index (BMI) was corrected by multiplying the self-reported estimate by its corresponding model coefficient and adding the model intercept. Paired $t$-tests were used to determine whether corrected mean BMI values were significantly more accurate (i.e., closer to measured data) than the equivalent means based on self-reported data. The analyses were repeated using the national equations. Results. Both the Atlantic and the national equations yielded corrected obesity estimates that were significantly more accurate than those based on self-report. Conclusion. The results provide some evidence of the generalizability of the national equations to atypical regions of Canada.
\end{abstract}

\section{Introduction}

Obesity is a major cause of morbidity in Canada and in many parts of the world and it is increasing worldwide [1]. As indicated by a body mass index (BMI) greater than or equal to $30 \mathrm{~kg} / \mathrm{m}^{2}$, obesity is a risk factor for cardiovascular disease, type 2 diabetes, several types of cancer, asthma, gallbladder disease, osteoarthritis, and chronic back pain $[1,2]$. Class II+ obesity $\left(\mathrm{BMI} \geq 35 \mathrm{~kg} / \mathrm{m}^{2}\right)$ is also associated with an increased risk of all-cause mortality [3]. Obesity and its associated comorbidities exact a heavy toll on health care systems and expenditures. In Canada, the 2006 direct medical cost of overweight and obesity was $\$ 6.0$ billion [4]. Against a global background comprising of 500 million obese adults [1], obesity has reached a historic high in Canada with one-quarter of adults and $9 \%$ of children meeting the definition [5].

Federal government statistical agencies, such as Statistics Canada and the National Center for Health Statistics, use large population-based studies to track nationwide obesity trends. Researchers usually use the BMI as a proxy to gauge obesity in these large national studies. According to Health Canada [6], although the BMI is not a direct measure of an individual's body fat, it is the most useful indicator of the health risks associated with under and overweight at a population level. In addition to using the BMI despite its limitations, large-scale research must rely heavily on selfreported obesity estimates, due to economic and logistical constraints, even though these estimates are distorted by reporting bias and error $[7,8]$. As a result of the bias and 
error, self-reported values underestimate the prevalence of obesity and, consequently, overestimate associations between excess body fat and chronic diseases [7-9].

Accurate obesity prevalence data are not only needed by public health planners and policy makers, but also by those who conduct obesity research. As direct BMI measurements, which are the gold standard for BMI data, are an expensive method of data collection, researchers have recently developed and recommended the use of correction equations based on measured data to correct self-reported values [7, 10-15]. However, correction equations are not without shortcomings. It has been established that correction equations can vary with time [16] and they are surveyand population specific [15]. For example, bias and error between self-reported BMI and physical measurements rise with increasing body weight [8]. Therefore, although Connor Gorber and colleagues $[7,15]$ generated correction equations in 2008 for Canadians in general and reassessed them in 2011, given that they are population-specific, they may not hold in atypical regions of Canada such as Atlantic Canada, which has unique sociodemographic characteristics and the highest obesity rates in the country [5]. The purpose of this study was to determine whether correction equations developed for the Canadian population were appropriate for use in Atlantic Canada and to compare the accuracy of the national equations to equations that were developed specifically for the Atlantic Canadian population.

\section{Methods}

This study involved a secondary data analysis of a large national representative survey, specifically the Canadian Community Health Survey (CCHS) 2007-2008, to answer the following main research question: how well do the national correction equations correct self-reported estimates of obesity in Atlantic Canada and is there a significant difference between Atlantic Canadian and national correction equations in yielding corrected obesity estimates that are closer to measured data, as compared to self-reported values? The study was approved by the Interdisciplinary Committee on Ethics in Human Research at Memorial University. Furthermore, study approval was obtained from Statistics Canada and the Social Sciences and Humanities Research Council of Canada (SSHRC).

The CCHS collects data on health status, health care utilization, and health determinants for the Canadian population [17]. Details of the 2007-2008 CCHS are published elsewhere $[17,18]$. They will be briefly summarized here. The target population of the 2007-2008 CCHS was persons aged 12 years and over living in private dwellings in all provinces and territories. The survey excludes persons living on Aboriginal reserves and settlements or in institutions, full-time members of the Canadian Forces, and residents of certain remote regions. The 2007-2008 CCHS had three sampling frames to select the sample of households: $49 \%$ of the sample of households came from an area frame, 50\% were from a list frame of telephone numbers, and 1\% came from a random digit dialing sampling frame. The national response rate for the CCHS 2007-2008 cycle was 78\% in 2007 and $75 \%$ in 2008, with a total of 131,959 Canadian respondents and 17,126 Atlantic respondents. The provincial response rates in the Atlantic region ranged from $77 \%$ to $82 \%$. Interviews were conducted between January 2007 and December 2008. Measured height and weight (MHW) data were collected in 2008 by trained interviewers with calibrated equipment for a subsample of about 5,000 Canadians [19]. In the Atlantic Canadian region, the provincial response rates for the MHW subsample ranged from $84 \%$ to $90 \%$ at the household level and from $51 \%$ to $67 \%$ for the direct measurement component, yielding overall response rates between $45 \%$ and $60 \%$. The MHW subsample size for the current study was 318 Atlantic Canadian adults. To minimize nonresponse bias, Statistics Canada created a sampling weight by redistributing the sampling weights of nonrespondents to respondents using response propensity classes.

The data analyses included all 2007-2008 CCHS Atlantic Canadian respondents, with the exception of pregnant and breastfeeding women and children under the age of 18 because the BMI is not intended for use with these groups [6]. Outliers, with differences between their self-reported and measured BMIs that were more than three standard deviations from the mean, were also excluded from the analyses. Descriptive analyses were conducted to describe the sociodemographic characteristics of the Atlantic Canadian population, as compared to the rest of Canada. Using the correction method employed by Connor Gorber et al. [7], Atlantic correction equations were developed in the MHW subsample. Multiple regression models were used to predict BMI using the self-reported counterpart as the independent variable. No other independent variables (e.g., age) were utilized, as it was previously shown that gains in predictive value were minimal for the Canadian population [7]. Self-reported BMI was corrected by multiplying the selfreported estimate by its corresponding model coefficient and adding the model intercept. The correction model, namely, $\mathrm{BMI}_{\text {measured }}=\mathrm{b}_{0}+\mathrm{b}_{1}\left(\right.$ bmi $\left._{\text {self-reported }}\right)+$ error, employed in this study was equivalent to that of Connor Gorber and colleagues' [7] Model 4. BMI estimates were derived with 95\% confidence intervals (CI) and exact variance estimates were computed using bootstrap methods. Since bias in BMI is known to differ by sex [8], all data analyses were run for males and females separately. We used the following Health Canada [6] BMI categories: underweight, BMI < 18.5; normal weight, $\mathrm{BMI}=18.5-24.9$; overweight, $\mathrm{BMI}=$ 25.0-29.9; obese, $\mathrm{BMI} \geq 30$. However, due to limited sample sizes, the underweight and normal weight categories were combined. The analyses were repeated using the published national correction equations [7]. Statistics Canada's guidelines for tabulation, analysis, and release were followed [17, 18]. For instance, Statistics Canada mandates that cells computed from fewer than 10 respondents are suppressed and estimates computed from 10 or more respondents with a coefficient of variation $(\mathrm{CV})$ between $16.6 \%$ and $33.3 \%$ are released with caution, while CVs greater than $33.3 \%$ are suppressed $[17,18]$. All data analyses were conducted at the Atlantic Research Data Centre (ARDC) at Dalhousie University using 
SAS 9.2 statistical software (SAS Institute Inc., Cary, NC, USA).

\section{Results}

Table 1 shows the sociodemographic characteristics of the 2007-2008 CCHS respondents from Atlantic Canada as compared to those from other regions of Canada. In Atlantic Canada, there were more females and full-time workers $(P<.01)$. Also, Atlantic respondents were significantly less educated and had lower household incomes than other Canadians $(P<.0001)$. Among the 2007-2008 CCHS respondents, residents of Atlantic Canada were more than twice as likely to live in a rural area. Besides being slightly older (mean age $=44.6$ years, 95\% CI $44.5-44.7$ versus 43.2 years, 95\% CI 43.2-43.3), Atlantic Canadians also differed significantly from their Canadian counterparts in terms of ethnicity and immigrant status. Most of those from the Atlantic region were white $(92.2 \%)$ and Canadian-born (95.3\%), compared to about three-quarters of Canadians $(P<.0001)$.

The correction equations for the Atlantic region were

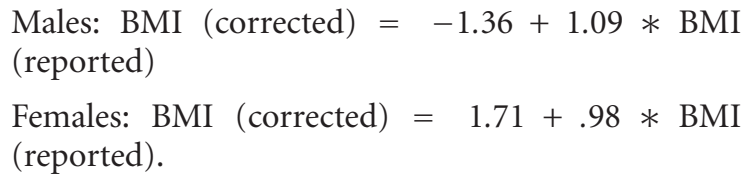

Table 2 displays information on the direction and magnitude of bias and error in self-reported BMI for both sexes in Atlantic Canada. A negative difference between self-reported and measured BMI indicates underreporting, whereas a positive difference indicates overreporting. Mean BMI values based on self-reported height and weight data were significantly lower $(P<.0001)$ than those based on measurements for both sexes. However, male and female corrected BMI means obtained from both the national and Atlantic-specific correction methods were not significantly different from their equivalent measured means. Men and women equally underreported their BMI by $1.4 \mathrm{~kg} / \mathrm{m}^{2}$ on average. The corrected BMI means were only $0.1-0.2 \mathrm{~kg} / \mathrm{m}^{2}$ and $0.3 \mathrm{~kg} / \mathrm{m}^{2}$ away from measurements for women and men, respectively.

We assessed trends in misreporting BMI across the different BMI categories. As presented in Table 3, the degree of misreporting varied by BMI category. With each categorical increase in BMI, the bias and error in self-reported BMI were magnified for both sexes. Therefore, underestimation of BMI was the highest among obese individuals, with obese men under-reporting their BMI by $2.6 \mathrm{~kg} / \mathrm{m}^{2}$ on average and obese women under-reporting their BMI by an average of $3.1 \mathrm{~kg} / \mathrm{m}^{2}$.

Table 3 also provides information on the performance of the national and the Atlantic correction equations across the different BMI categories. For both equations, among men who were underweight or normal weight, both self-reported and corrected BMI means were not significantly different than their measured counterpart. Among women who were underweight or normal weight, the self-reported BMI mean was not significantly different from the measured mean, but this was not the case for either corrected mean. With respect to overweight or obese men and women, the corrected BMI means were more accurate (i.e., closer to the corresponding measured mean) than the comparable means calculated from self-reported data. Indeed, for overweight men and women, the corrected BMI means were significantly better than the equivalent self-reported means and they were identical or nearly identical to the BMI means based on measurements.

\section{Discussion}

While recognizing their deficiencies, researchers use selfreported BMI data out of necessity in large surveys [8], such as the CCHS in Canada and the National Health Interview Survey in the United States. Initial attempts to correct BMI values based on self-report led Plankey et al. [20] to publicize in 1997 that prediction equations do not eliminate systematic error in self-reported BMI data. Although corrected estimates are not usually identical to direct measurements, in recent years, BMI correction equations have been more successful at bridging the gap between self-reported numbers and measurements [7, 9-15]. The recent success of correction equations may be partly due to the changing nature of the reporting bias/error itself [7]. Since the dawn of correction equations, reporting bias and error have doubled in Canada, which improves the odds of having corrected BMI values that are significantly closer to physical measurements than their corresponding selfreported figures $[7,16]$. The latest correction equations show great promise, notwithstanding some caveats for their use. As reporting bias and error can vary from one population to the next and they may not be stable over time [16], correction equations need to be developed specifically for a particular population and monitored periodically [15]. In addition, as observed in this and another Canadian study [7], while the equations bring self-reported overweight and obesity estimates closer to measured values, which is important in this line of research $[7,8,23]$, it should be noted that this process skews the underweight and normal weight data.

Atlantic Canada holds the unfavourable distinction of having the highest obesity rates in the country [5]. Moreover, the results of our present analysis comparing Atlantic Canada with the rest of the nation on a number of sociodemographic characteristics demonstrate that Atlantic Canadians are distinct from other Canadians in several respects. Given that correction equations are population specific, we compared the national equations with the ones we developed specifically for this unique region of Canada. Both correction equations significantly improved the accuracy of self-reported Atlantic Canadian obesity data. The results of the current study suggest that the national equations, which are starting to be used elsewhere in the country [3], are generalizable even to atypical regions of Canada. The success of the correction equations used herein also corroborates current assertions by international researchers [7, 10-15] that these equations provide better obesity estimates than those based on self-report. 
TABle 1: Comparison of sociodemographic characteristics between Canada and the Atlantic region, 2007-2008.

\begin{tabular}{|c|c|c|c|c|}
\hline \multirow{2}{*}{ Characteristic } & \multicolumn{2}{|r|}{ Canada } & \multicolumn{2}{|c|}{ Atlantic region } \\
\hline & $\%$ & 95\% confidence interval & $\%$ & 95\% confidence interval \\
\hline \multicolumn{5}{|l|}{ Sex } \\
\hline Female & 50.7 & $50.6,50.7$ & $51.5^{+}$ & $51.3,51.7$ \\
\hline Male & 49.4 & $49.3,49.4$ & $48.5^{\dagger}$ & $48.3,48.7$ \\
\hline \multicolumn{5}{|l|}{ Education } \\
\hline Some secondary & 22.6 & $22.3,23.0$ & $28.0^{\dagger}$ & $27.1,28.8$ \\
\hline Secondary, No postsecondary & 15.6 & $15.2,15.9$ & 14.5 & $13.8,15.2$ \\
\hline Some postsecondary & 8.4 & $8.1,8.7$ & 8.1 & $7.6,8.7$ \\
\hline postsecondary & 53.4 & $52.9,53.9$ & $49.4^{\dagger}$ & $48.5,50.4$ \\
\hline \multicolumn{5}{|l|}{ Degree/diploma } \\
\hline \multicolumn{5}{|l|}{ Area of residence } \\
\hline Urban & 71.9 & $71.3,72.5$ & $38.6^{+}$ & $37.0,40.1$ \\
\hline Rural & 28.1 & $27.5,28.7$ & $61.5^{\dagger}$ & $59.9,63.0$ \\
\hline \multicolumn{5}{|l|}{ Employment status } \\
\hline Employed full-time & 83.3 & $82.9,83.7$ & $84.8^{*}$ & $83.8,85.8$ \\
\hline Employed part-time & 16.7 & $16.3,17.1$ & $15.2^{*}$ & $14.3,16.2$ \\
\hline \multicolumn{5}{|l|}{ Immigrant status } \\
\hline Canadian-born & 75.2 & $74.7,75.7$ & $95.3^{\dagger}$ & $94.8,95.8$ \\
\hline Foreign-born & 24.8 & $24.3,25.3$ & $4.7^{\dagger}$ & $4.2,5.3$ \\
\hline \multicolumn{5}{|l|}{ Ethnicity } \\
\hline White & 77.0 & $76.3,77.7$ & $92.2^{\dagger}$ & $91.5,92.8$ \\
\hline Visible minority & 23.0 & $22.4,23.7$ & $7.8^{\dagger}$ & $7.2,8.5$ \\
\hline Mean household income & $\$ 78,135$ & $\$ 77,309, \$ 78,960$ & $\$ 64,271^{\dagger}$ & $\$ 62,877, \$ 65,666$ \\
\hline Mean age & 43.2 & $43.2,43.3$ & $44.6^{\dagger}$ & $44.5,44.7$ \\
\hline
\end{tabular}

* Significantly different from estimate for Canada $(P<0.01)$.

${ }^{\dagger}$ Significantly different from estimate for Canada $(P \leq 0.0001)$.

Data source: 2007-2008 Canadian Community Health Survey, Statistics Canada.

TABLE 2: Mean body mass index (BMI) and mean difference between measured and self-reported or corrected BMI, by collection method and sex, household population aged 18 years or older, Atlantic Canada, 2007-2008.

\begin{tabular}{|c|c|c|c|c|c|c|c|c|c|c|}
\hline \multirow{2}{*}{$\begin{array}{l}\text { Mean BMI } \\
\left(\mathrm{kg} / \mathrm{m}^{2}\right)\end{array}$} & \multicolumn{2}{|c|}{ Collection method } & \multicolumn{2}{|c|}{ Correction method } & \multicolumn{6}{|c|}{ Difference } \\
\hline & Measured & SR & $\begin{array}{l}\text { Atlantic } \\
\text { CEs }\end{array}$ & $\begin{array}{l}\text { National } \\
\text { CEs }\end{array}$ & $\begin{array}{l}\text { SR minus } \\
\text { measured }\end{array}$ & $\begin{array}{c}95 \% \\
\mathrm{CI}\end{array}$ & $\begin{array}{l}\text { Atlantic corrected } \\
\text { minus measured }\end{array}$ & $\begin{array}{c}95 \% \\
\mathrm{CI}\end{array}$ & $\begin{array}{l}\text { National corrected } \\
\text { minus measured }\end{array}$ & $\begin{array}{c}95 \% \\
\mathrm{CI} \\
\end{array}$ \\
\hline Both sexes & 28.4 & $27.0^{*}$ & 28.2 & 28.3 & -1.4 & $\begin{array}{l}-1.7 \\
-1.0\end{array}$ & -0.2 & $\begin{array}{c}-0.6 \\
0.1\end{array}$ & -0.1 & $\begin{array}{c}-0.4 \\
0.3\end{array}$ \\
\hline Males & 29.1 & $27.7^{*}$ & 28.8 & 28.8 & -1.4 & $\begin{array}{l}-2.0 \\
-0.8\end{array}$ & -0.3 & $\begin{array}{c}-0.9 \\
0.3\end{array}$ & -0.3 & $\begin{array}{c}-0.9 \\
0.3\end{array}$ \\
\hline Females & 27.7 & $26.3^{*}$ & 27.5 & 27.8 & -1.4 & $\begin{array}{l}-1.9 \\
-0.9\end{array}$ & -0.2 & $\begin{array}{c}-0.7 \\
0.3\end{array}$ & 0.1 & $\begin{array}{c}-0.4 \\
0.6\end{array}$ \\
\hline
\end{tabular}

*Significantly different from measured estimate $(P<0.0001)$.

Abbreviations: CE, correction equation; CI, confidence interval; SR, self-reported.

Data source: 2007-2008 Canadian Community Health Survey, Statistics Canada.

In keeping with other studies [7-16, 22-24], mean BMI based on self-reported height and weight data was significantly lower than mean BMI based on measurements. In the current study, the direction and degree of BMI misreporting were identical for men and women. Most of the research in this area demonstrated that the trend of underreporting was slightly more pronounced among women [7, $8,10,11,13-16,22-24]$. In sharp contrast, Jain [12] found that under-reporting of obesity prevalence in the United States was $0.7 \%$ lower in females than in males. Perhaps the context of the survey used by Jain (i.e., the National Health and Nutrition Examination Survey (NHANES)) played a role in the anomalous finding. As pointed out in a recent publication [15], bias in self-reported BMI depends on survey context, such as whether or not respondents know they will be measured when they report their weight and 
TABLE 3: Mean body mass index (BMI) and mean difference between measured and self-reported or corrected BMI, by collection method, sex, and BMI category, household population aged 18 years or older, Atlantic Canada, 2007-2008.

\begin{tabular}{|c|c|c|c|c|c|c|c|c|c|c|}
\hline \multirow{3}{*}{$\begin{array}{l}\text { BMI category } \\
\left(\text { range } \mathrm{kg} / \mathrm{m}^{2}\right)\end{array}$} & \multicolumn{4}{|c|}{ Mean BMI } & \multicolumn{6}{|c|}{ Mean difference } \\
\hline & \multicolumn{2}{|c|}{ Collection method } & \multicolumn{2}{|c|}{ Correction method } & \multirow{2}{*}{$\begin{array}{l}\text { SR minus } \\
\text { measured }\end{array}$} & \multirow{2}{*}{$\begin{array}{c}95 \% \\
\mathrm{CI}\end{array}$} & \multirow{2}{*}{$\begin{array}{l}\text { Atlantic corrected } \\
\text { minus measured }\end{array}$} & \multirow{2}{*}{$\begin{array}{c}95 \% \\
\text { CI }\end{array}$} & \multirow{2}{*}{$\begin{array}{l}\text { National corrected } \\
\text { minus measured }\end{array}$} & \multirow{2}{*}{$\begin{array}{c}95 \% \\
\mathrm{CI}\end{array}$} \\
\hline & Measured & SR & $\begin{array}{l}\text { Atlantic } \\
\text { CEs }\end{array}$ & $\begin{array}{l}\text { National } \\
\text { CEs }\end{array}$ & & & & & & \\
\hline \multicolumn{11}{|c|}{ Both sexes } \\
\hline UW and NW $(<24.9)$ & 22.7 & 22.5 & $23.6^{*}$ & $23.6^{*}$ & -0.2 & $\begin{array}{c}-0.7 \\
0.3\end{array}$ & 0.9 & $\begin{array}{l}0.3 \\
1.5\end{array}$ & 0.9 & $\begin{array}{l}0.3 \\
1.4\end{array}$ \\
\hline OW (25.0 to 29.9$)$ & 27.6 & $26.5^{*}$ & 27.6 & 27.7 & -1.1 & $\begin{array}{l}-1.6 \\
-0.7\end{array}$ & -0.0 & $\begin{array}{c}-0.5 \\
0.4\end{array}$ & 0.1 & $\begin{array}{c}-0.4 \\
0.5\end{array}$ \\
\hline Obese (30.0 or more) & 34.8 & $32.0^{*}$ & $33.3^{*}$ & $33.5^{*}$ & -2.8 & $\begin{array}{l}-3.6 \\
-2.1\end{array}$ & -1.6 & $\begin{array}{l}-2.3 \\
-0.8\end{array}$ & -1.3 & $\begin{array}{l}-2.0 \\
-0.5\end{array}$ \\
\hline \multicolumn{11}{|c|}{ Males } \\
\hline UW and NW $(<24.9)$ & 23.5 & 23.4 & 24.2 & 24.2 & -0.1 & $\begin{array}{c}-1.4 \\
1.1\end{array}$ & 0.6 & $\begin{array}{c}-0.8 \\
2.0\end{array}$ & 0.7 & $\begin{array}{c}-0.7 \\
2.0\end{array}$ \\
\hline OW (25.0 to 29.9 ) & 27.6 & $26.6^{*}$ & 27.6 & 27.6 & -1.0 & $\begin{array}{l}-1.3 \\
-0.6\end{array}$ & 0.1 & $\begin{array}{c}-0.3 \\
0.4\end{array}$ & 0.1 & $\begin{array}{c}-0.3 \\
0.4\end{array}$ \\
\hline Obese (30.0 or more) & 34.1 & $31.5^{*}$ & $32.9^{*}$ & $32.9^{*}$ & -2.6 & $\begin{array}{l}-3.6 \\
-1.7\end{array}$ & -1.2 & $\begin{array}{l}-2.2 \\
-0.2\end{array}$ & -1.2 & $\begin{array}{l}-2.2 \\
-0.2 \\
\end{array}$ \\
\hline \multicolumn{11}{|c|}{ Females } \\
\hline UW and NW $(<24.9)$ & 22.3 & 22.1 & $23.4^{*}$ & $23.3^{*}$ & -0.2 & $\begin{array}{c}-0.8 \\
0.3\end{array}$ & 1.0 & $\begin{array}{l}0.5 \\
1.6\end{array}$ & 1.0 & $\begin{array}{c}0.4 \\
1.6\end{array}$ \\
\hline OW (25.0 to 29.9 ) & 27.6 & $26.3^{*}$ & 27.5 & 27.8 & -1.3 & $\begin{array}{l}-2.3 \\
-0.4\end{array}$ & -0.2 & $\begin{array}{c}-1.1 \\
0.8\end{array}$ & 0.1 & $\begin{array}{c}-0.9 \\
1.1\end{array}$ \\
\hline Obese (30.0 or more) & 35.7 & $32.6^{*}$ & $33.7^{*}$ & $34.4^{*}$ & -3.1 & $\begin{array}{l}-4.3 \\
-1.9 \\
\end{array}$ & -2.0 & $\begin{array}{l}-3.2 \\
-0.9 \\
\end{array}$ & -1.3 & $\begin{array}{l}-2.5 \\
-0.1 \\
\end{array}$ \\
\hline
\end{tabular}

${ }^{*}$ Significantly different from estimate for measured $(P<0.05)$.

Abbreviations: CE, correction equation; CI, confidence interval; NW, normal weight; OW, overweight; SR, self-reported; UW, underweight.

Data Source: 2007-2008 Canadian Community Health Survey, Statistics Canada.

height. In the NHANES, at the time of self-reported weight and height, respondents are aware that they will later be measured, which is not the case for the CCHS.

In the current study, underestimation of BMI increased with excess body fat. Other researchers $[7,9,10,12-14,22-$ 24] documented similar results. In a Canadian national study [8], this relationship was only observed outside of the underweight category for men and women alike. Among those who were underweight, BMI was overestimated by males, but there was no significant difference between selfreported and measured BMI for females. Corresponding results were found among American college students [11]. In the current study, we merged the underweight and normal weight BMI categories due to small sample sizes. Thus, we cannot directly compare our findings with the two publications. Notwithstanding this difference, we observed no significant difference between self-reported and measured BMI for males and females in the underweight and normal weight category.

The present study also adds to the existing research literature in two important ways. First, we present measured BMI data for a subset of Atlantic adults. Canadian regional statistics on levels of obesity are normally derived from selfreport questionnaires on account of sample size limitations for measured data [5]. Our measured BMI results suggest that obesity may be at a record level in this region of the country. The data analysis revealed a measured mean BMI of $29.1 \mathrm{~kg} / \mathrm{m}^{2}$ (95\% CI $\left.28.0-30.1\right)$ for men and $27.7 \mathrm{~kg} / \mathrm{m}^{2}$ (95\% CI 26.6-28.9) for women in the Atlantic region in 2008. According to an analysis of Canadian Health Measures Survey data [15], the measured mean BMI for Canadian men was $27.5 \mathrm{~kg} / \mathrm{m}^{2}(95 \%$ CI $27.1-27.9)$ and it was $26.6 \mathrm{~kg} / \mathrm{m}^{2}$ (95\% CI 25.9-27.4) for Canadian women from 2007 to 2009.

Second, this study is innovative in that it equips researchers with data supporting the utilization of the national correction equations throughout the Atlantic region in the absence of measured data. The national equations could be used in future analyses of self-reported BMI data from the CCHS in any or all of the four Atlantic provinces. Bearing in mind the considerable attention drawn to the issue of obesity by health authorities and researchers in the region [25], future research using obesity estimates lies ahead. As it currently stands, a cursory search of PubMed, using the search terms "obesity" and "Atlantic Canada," retrieved 135 citations in the last five years alone. Since obesity prevalence data are the foundation of some other obesity-related research analyses, the accuracy of prevalence data is essential. The application of the national correction equations should strengthen research conducted with selfreported Atlantic Canadian obesity data. 
Journal of Obesity

There are some limitations of this study that deserve consideration. Due to small numbers, we could not maintain separate BMI categories for those who were underweight and those who were of normal weight, which precluded a more refined analysis for these groups. Ideally, we would have had a larger subsample size to compute the correction equations for the Atlantic region. However, we used the best data and the largest subsample size available. Furthermore, the regression models used to compute the correction equations for both sexes were highly significant $(F(1,188)=1185.8$, $P<.0001$ and $F(1,108)=593.0, P<.0001$ for females and males, respectively) and the $\mathrm{CV}$ for the estimate from either model was less than 7.0, indicating that the level of precision was well within acceptable limits. Another study limitation concerned the response rate. In Atlantic Canada, the provincial overall response rates for the MHW subsample were between $45 \%$ and $60 \%$, but this was similar to the response rate for the MHW subsample for the rest of the country [15]. Although a sampling weight created by Statistics Canada was used to adjust for differential participation rates, if the characteristics of non-respondents, such as mean BMI, were significantly different than respondents, then nonresponse bias may have tainted the study. An additional study limitation involved the measurement of height and weight. Trained interviewers and calibrated equipment were used to collect the data [19], but we cannot exclude significant measurement error as intra- and interrater reliability were not evaluated. Also, although the BMI is frequently used to measure adiposity at the population level, there are welldocumented limitations of the BMI as a tool to quantify body fat [26]. Furthermore, Shields and colleagues [7, 9, 15] caution against the indiscriminate use of correction equations because they can change over time [16] and they are dependent upon the population and survey context. For the particular correction method used in this study, sensitivity values are reduced for the normal weight population. In other words, while postcorrection percentages provide a more accurate estimation of overweight and obesity, the precorrection percentages are a better estimation of normal weight because the reporting bias and error are lower in this BMI category [7].

\section{Conclusions}

This study provides some evidence of the generalizability of the national correction equations to atypical regions of Canada. Also, the results of this study add to a small, but accumulating body of research supporting the efficacy of BMI correction equations. In light of reports that selfreported BMI statistics underestimate the prevalence of obesity and overestimate associations between obesity and chronic diseases $[7,8,23]$, we strongly recommend the use of correction equations to other researchers analysing obesity data collected by self-report. In particular, given the nature of BMI correction equations, we recommend that Canadian researchers use the national correction equations [7] in the absence of measured data or compute their own correction equations if they have measured and self-reported obesity data.

\section{Conflict of Interests}

The authors declare that they have no conflict of interests.

\section{References}

[1] World Health Organization, "Obesity and overweight," 2012, http://www.who.int/mediacentre/factsheets/fs311/en/index .html.

[2] D. P. Guh, W. Zhang, N. Bansback, Z. Amarsi, C. L. Birmingham, and A. H. Anis, "The incidence of co-morbidities related to obesity and overweight: a systematic review and meta-analysis," BMC Public Health, vol. 9, article 88, pp. 1-20, 2009.

[3] H. M. Orpana, J. M. Berthelot, M. S. Kaplan, D. H. Feeny, B. McFarland, and N. A. Ross, "BMI and mortality: results from a national longitudinal study of Canadian adults," Obesity, vol. 18, no. 1, pp. 214-218, 2010.

[4] A. H. Anis, W. Zhang, N. Bansback, D. P. Guh, Z. Amarsi, and C. L. Birmingham, "Obesity and overweight in Canada: an updated cost-of-illness study," Obesity Reviews, vol. 11, no. 1, pp. 31-40, 2010.

[5] Public Health Agency of Canada and the Canadian Institute for Health Information, Obesity in Canada, The Agency and Institute, Ottawa, Canada, 2011.

[6] Health Canada, "Canadian guidelines for body weight classification in adults: Quick reference tool for professionals," 2008, http://www.hc-sc.gc.ca/fn-an/nutrition/weightspoids/guide-ld-adult/cg_quick_ref-ldc_rapide_ref-eng .php.

[7] S. Connor Gorber, M. Shields, M. S. Tremblay, and I. McDowell, "The feasibility of establishing correction factors to adjust self-reported estimates of obesity," Health Reports, vol. 19, no. 3, pp. 71-82, 2008.

[8] M. Shields, S. Connor Gorber, and M. S. Tremblay, "Estimates of obesity based on self-report versus direct measures," Health Reports, vol. 19, no. 2, pp. 61-76, 2008.

[9] M. Shields, S. Connor Gorber, and M. S. Tremblay, "Effects of measurement on obesity and morbidity," Health Reports, vol. 19, no. 2, pp. 77-84, 2008.

[10] A. J. Hayes, P. M. Clarke, and T. W. C. Lung, "Change in bias in self-reported body mass index in Australia between 1995 and 2008 and the evaluation of correction equations," Population Health Metrics, vol. 9, Article ID 53, 2011.

[11] A. Mozumdar and G. Liguori, "Correction equations to adjust self-reported height and weight for obesity estimates among college students," Research Quarterly for Exercise and Sport, vol. 82, no. 3, pp. 391-399, 2011.

[12] R. B. Jain, "Regression models to predict corrected weight, height and obesity prevalence from self-reported data: data from BRFSS 1999-2007," International Journal of Obesity, vol. 34, no. 11, pp. 1655-1664, 2010.

[13] M. Nyholm, B. Gullberg, J. Merlo, C. Lundqvist-Persson, L. Råstam, and U. Lindblad, "The validity of obesity based on self-reported weight and height: implications for population studies," Obesity, vol. 15, no. 1, pp. 197-208, 2007.

[14] M. Ezzati, H. Martin, S. Skjold, S. Vander Hoorn, and C. J. L. Murray, "Trends in national and state-level obesity in the USA after correction for self-report bias: analysis of health surveys," Journal of the Royal Society of Medicine, vol. 99, no. 5, pp. 250257, 2006.

[15] M. Shields, S. Connor Gorber, I. Janssen, and M. S. Tremblay, "Bias in self-reported estimates of obesity in Canadian health surveys: an update on correction equations for adults," Health 
Reports, vol. 22, no. 3, pp. 35-45, 2011.

[16] S. Connor Gorber and M. S. Tremblay, "The bias in selfreported obesity from 1976 to 2005: a Canada-US comparison," Obesity, vol. 18, no. 2, pp. 354-361, 2010.

[17] Statistics Canada, "Canadian Community Health Survey (CCHS): 2007 Microdata files user guide,” 2008, http://www .statcan.gc.ca/imdb-bmdi/document/3226_D7_T9_V4-eng. pdf.

[18] Statistics Canada, "Canadian Community Health Survey (CCHS)-Annual component: user guide 2008 microdata files," 2009, http://www.statcan.gc.ca/imdb-bmdi/document/3226 D7_T9_V5-eng.pdf.

[19] J. Pedro, "Study on the reliability of the weighing scales used in the 2008 Canadian Community Health Survey (CCHS) for the measured height and weight (MHW) module," 2009, http://www.statcan.gc.ca/imdb-bmdi/document/3226_D63_ T9_V1-eng.htm.

[20] M. W. Plankey, J. Stevens, K. M. Flegal, and P. F. Rust, "Prediction equations do not eliminate systematic error in self-reported body mass index," Obesity Research, vol. 5, no. 4, pp. 308-314, 1997.

[21] A. Chiolero, I. Peytremann-Bridevaux, and F. Paccaud, "Associations between obesity and health conditions may be overestimated if self-reported body mass index is used," Obesity Reviews, vol. 8, no. 4, pp. 373-374, 2007.

[22] F. J. Elgar and J. M. Stewart, "Validity of self-report screening for overweight and obesity: evidence from the Canadian community health survey," Canadian Journal of Public Health, vol. 99, no. 5, pp. 423-427, 2008.

[23] M. Yannakoulia, D. B. Panagiotakos, C. Pitsavos, and C. Stefanadis, "Correlates of BMI misreporting among apparently healthy individuals: the ATTICA study," Obesity, vol. 14, no. 5, pp. 894-901, 2006.

[24] J. Gil and T. Mora, "The determinants of misreporting weight and height: the role of social norms," Economics and Human Biology, vol. 9, no. 1, pp. 78-91, 2011.

[25] J. L. Grant, K. C. MacKay, P. M. Manuel, and T. L. F. McHugh, "Barriers to optimizing investments in the built environment to reduce youth obesity: policy-maker perspectives," Canadian Journal of Public Health, vol. 101, no. 3, pp. 237-240, 2010.

[26] World Health Organization, "Body mass index," 2012, http://www.euro.who.int/en/what-we-do/health-topics/disease-prevention/nutrition/a-healthy-lifestyle/body-massindex-bmi. 


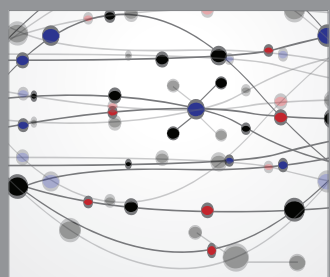

The Scientific World Journal
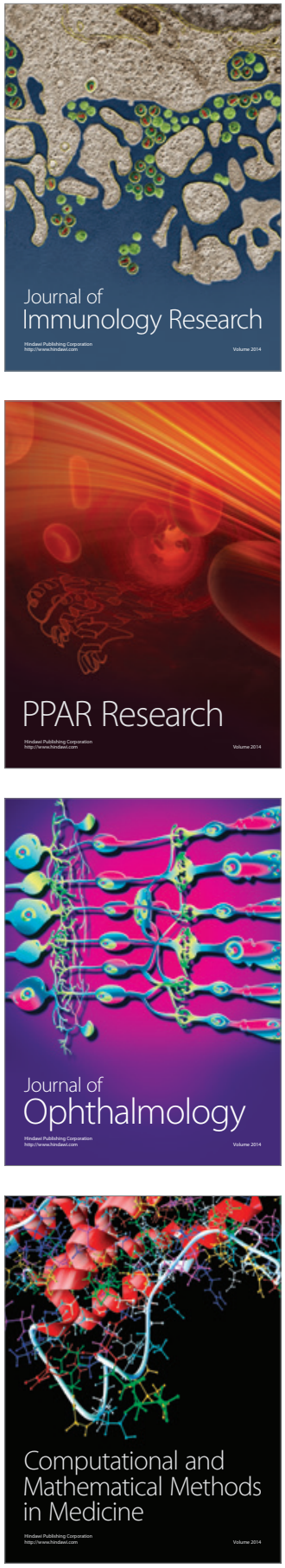

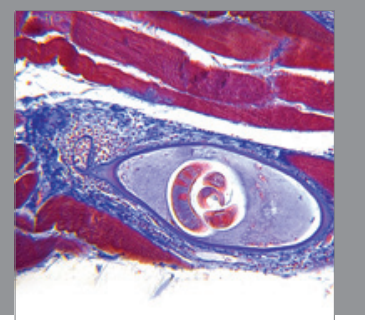

Gastroenterology

Research and Practice
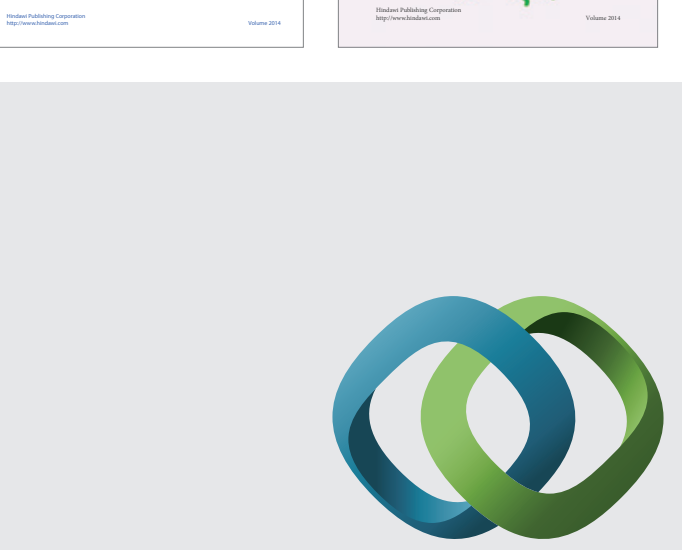

\section{Hindawi}

Submit your manuscripts at

http://www.hindawi.com
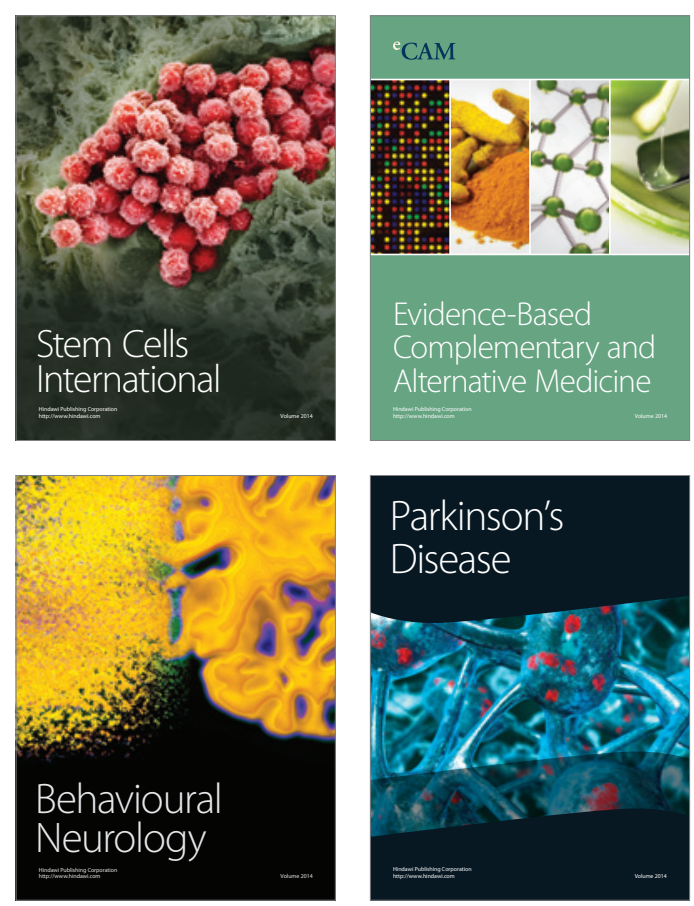

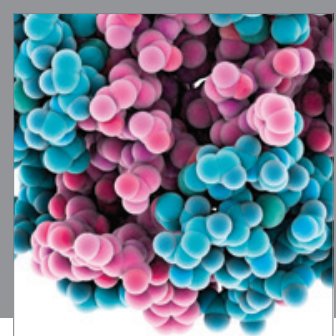

Journal of
Diabetes Research

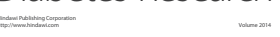

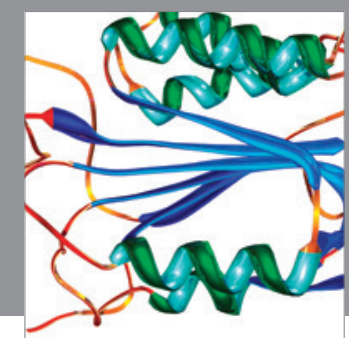

Disease Markers
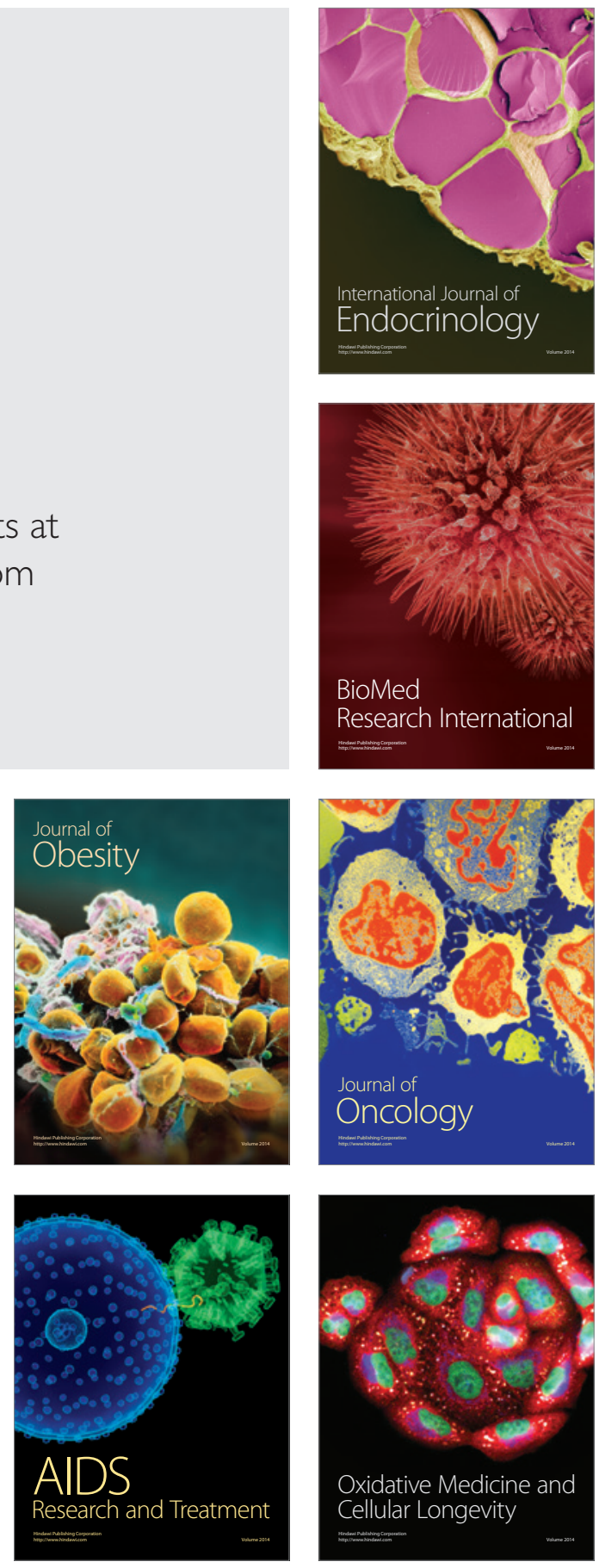